\title{
In vitro Anticancer Activity and Antioxidant Properties of Essential Oils from Populus alba L. and Rosmarinus officinalis L. from South Eastern Anatolia of Turkey
}

\author{
Sevgi Gezici ${ }^{1}$, Nazim Sekeroglu², Anake Kijjoa ${ }^{3}$ \\ 1Department of Biology, University of Gaziantep, Gaziantep, Turkey, sevgigezici.00@gmail.com \\ ${ }^{2}$ Department of Medicinal and Aromatic Plants, University of Kilis 7 Aralik, Kilis, Turkey, nsekeroglu@gmail.com \\ ${ }^{3}$ Instituto de Ciências Biomédicas Abel Salazar, University of Porto, Porto, Portugal, ankijjoa@icbas.up.pt
}

\begin{abstract}
Background and Purpose: In recent years, essential oils (EOs) have been reported to possess interesting anti-tumor, anti-mutagenic and anti-carcinogenic activities against various cancer cells. Therefore, we aimed to investigate potential biological activities of EOs from white poplar (Populus alba L., Salicaceae) and rosemary (Rosmarinus officinalis L., Lamiaceae). Material and Methods: EOs from $P$. alba L. and $R$. officinalis L. were extracted by hydrodistillation. MTT assay was carried out to determine the potential antiproliferative and cytotoxic properties of the essential oils as well as their corresponding $\mathrm{IC}_{50}$, and the inhibition (\%) calculated. Antioxidant activity was determined using 2,2-diphenyl-2-picrylhydrazyl (DPPH) assay, and lipid peroxidation capacity was evaluated using thiobarbituric acid-reactive substances (TBARS) method, and the values were calculated using the standards. Results: The EOs were evaluated for their in vitro cytotoxic, antioxidant and lipid oxidation activities. Regarding cytotoxic activity rosemary essential oil possessed strong inhibition $\left(\mathrm{IC}_{50}=3.06-7.38 \mu \mathrm{g} / \mathrm{mL}\right)$ of cell proliferation in comparison to that of $P$. alba L. $\left(\mathrm{IC}_{50}=10.53-28.16 \mu \mathrm{g} / \mathrm{mL}\right)$. Additionally, EO from $R$. officinalis $\mathrm{L}$. was found to have higher antioxidant and lipid peroxidation capacities with $\mathrm{IC}_{50}$ of $10.08 \pm 0.15$ and $1.76 \pm 0.01$, respectively. Conclusion: The results suggest that the EOs of both sources exhibited strong antiproliferative, cytotoxic and potent antioxidant properties and therefore they can have potential applications in the cancer treatment.
\end{abstract}

KEY WORDS: Cytotoxicity, Populus alba L., Rosmarinus officinalis L., DPPH, EOs, MTT, TBARS, IC ${ }_{50}$.

\section{INTRODUCTION}

Medicinal and aromatic plants (MAPs) have been used in traditional medicine in all parts of the world since the ancient times, and nowadays interest in using both different MAPs and products derived from MAPs have continued almost in all sectors and industries. ${ }^{1,2}$ In recent years, a large number of secondary metabolites, including essential oils (EOs) are considered as valuable sources for ingredients in food and pharmaceutical industries, cosmetics and medicinal applications for prevention and/or treatment of many diseases including neurodegenerative diseases, rheumatoid arthritis, diabetes, respiratory diseases, cardiovascular diseases, cancers and inflammatory and oxidative diseases. $^{2,3}$ EOs extracted from MAPs, contain 300 compounds such as limonene, $\alpha$-pinene, $\beta$-myrcene, $\beta$-elemene, caryophyllene, humulene, $\alpha$-farnesene, cembrene, kaurene, eucalyptol, camphorene, camphor, carveol, limonene oxide, caryophyllene oxide, farnesol, humulene epoxide, $\alpha$-bisabolene oxide, carvacrol, catechol, eugenol, isopropyl
DOI: 10.5530/ijper.51.3s.74 Correspondence: Sevgi Gezici, Department of Biology, University of Gaziantep, Gaziantep, Turkey Contact: +90 5324015512 E-Mail: sevgigezici.00@ gmail.com

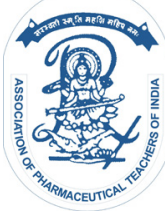

www.ijper.org 
alcohol, butyl alcohol, perillyl alcohol, geraniol, nerol, safrole, sesquiterpenes, rosmarinic acid, nerolidol, benzophenone, bornyl acetate, ethyl acetate, vernolide, cinnamaldehyde, acetophenone, helenin, fumarin, benzofuran etc., that exhibit many biological properties including antibacterial, antifungal, antioxidant, antiulcer, antispasmodic, antiproliferative, antitumor, antihepatotoxic, and others. EOs have thus become a focal point to improve and maintain human health needs and treatment of the diseases with less side effects. ${ }^{3-5}$

Previous researches both in vivo and in vitro showed that EOs possess major bioactive components and molecules, which have chemoprevention and cancer suppression activities. EOs have also been demonstrated to have potentials to fight against cancer cells by multiple pathways and mechanisms, including of apoptosis and cell cycle arrest, angiogenesis and cell proliferation, of DNA damage and to repair signaling and activation of detoxification enzymes such as glutathione reductase, catalase glutathione, superoxide dismutase, peroxidase, etc. ${ }^{2-5}$

R. officinalis L., also known as rosemary, is native to the Mediterranean region and grown in many parts of the world. Possesses a wide range of biological activities and medicinal uses, particularly for the treatment of central nervous system complaints, liver, respiratory and genito-urinary disorders, cancer gastrointestinal and cardiovascular diseases. ${ }^{6-8}$ In addition to its medicinal uses, it has been used for culinary, food flavoring and spice, cosmetics, and perfumery applications. ${ }^{9,10}$ Recent studies revealed that rosemary EOs have greater biological effects than its extracts since the EOs have higher contents of major bioactive components, especially polyphenols and phenylpropanoids such as rosmarinic acid, carnosic acids, camphor, camphene, $\alpha$-pinene, $\beta$-pinene, borneol, caryophyllene, limonene, terpineol and myrcene. ${ }^{8-12} P$. alba L., known as white poplar, growing in a wide range of environmental conditions, is belonging to the family Salicaceae and native to central and southern Europe. ${ }^{13}$ Although there were some previous investigations on the EO of $\mathrm{P}$. alba, to the best of our knowledge, this is the first report of its in vitro anticancer and antiproliferative activities.

Contrary to rosemary extracts, which have been widely investigated for their anticancer effects, the EOs of rosemary and white poplar have not yet been thoroughly investigated for their biological activities especially antioxidant, antiproliferative and cytotoxic properties. Therefore, we have evaluated potential antioxidant properties, lipid peroxidation capacity, in vitro cytotoxic and antiproliferative activities of EOs extracted from P. alba L. and R. officinalis $\mathrm{L}$. against three human cancer cell lines: A549 cells (human lung adenocarcinoma),
H1299 (human non-small lung cancer) and MCF-7 (human breast adenocarcinoma), obtained from the American Type Culture Collection (ATCC).

\section{MATERIALS AND METHODS}

Plant material: The aerial parts of $P$. alba $L$. and $R$. officinalis $\mathrm{L}$. were collected from Gaziantep, south eastern Anatolia of Turkey, and kept at laboratory conditions at room temperature $\left(25^{\circ} \mathrm{C}\right)$ with no direct light until the extraction.

Extraction of EOs: The leaves and flowers of P. alba L. and R. officinalis L. were used for extraction of EOs. All the plant parts (100 g for each plant species) were extracted separately by hydrodistillation using a Clevenger Apparatus for $4 \mathrm{~h}$ at $100 \pm 5^{\circ} \mathrm{C}$, and the extracted oils were dried over anhydrous $\mathrm{Na}_{2} \mathrm{SO}_{4}$, then the pure essential oils were obtained and stored at $4^{\circ} \mathrm{C}$ for further analysis.

In vitro anticancer activity assay by MTT method: MTT assay was carried out to determine the potential antiproliferative and cytotoxic properties of the EOs from $P$. alba L. and R. officinalis L. against three human cancer cell lines: A549 cells (human lung adenocarcinoma), H1299 (human non-small cell lung cancer), MCF-7 (human breast adenocarcinoma), and non-tumor HUVEC cells, obtained from the American Type Culture Collection (ATCC). MTT assay was performed as previously reported by Al-Qubaisi et al. ${ }^{14}$ with minor modifications. Cells were cultured on RPMI-1640 medium, supplemented with $10 \%$ fetal bovine serum, $100 \mathrm{U} / \mathrm{mL}$ penicillin and $100 \mu \mathrm{g} / \mathrm{mL}$ streptomycin in the flasks with $5 \% \mathrm{CO}_{2}$ at $37^{\circ} \mathrm{C}$. The $5 \times 10^{3}$ cells per $\mathrm{mL}$ were treated with EOs with concentrations of 0 , $1,10,100 \mu \mathrm{M}$, and incubated at $37^{\circ} \mathrm{C}$ for $48 \mathrm{~h}$. After incubation, $50 \mu \mathrm{L} /$ well of MTT solution was added into each well, then the OD was measured at $570 \mathrm{~nm}$ and the inhibition (\%) was calculated as;

[(mean OD without test agent (negative control) - mean $\mathrm{OD}$ with test agent / mean OD without test agent (negative control)] $\times 100$

In vitro antioxidant activity assay by DPPH method: Antioxidant activity was determined using microplate 2,2-diphenyl-2-picrylhydrazyl (DPPH) assay described by Molyneux ${ }^{15}$ with some modifications. Ascorbic acid was used as standard. The absorbance value was measured at $517 \mathrm{~nm}$ using a spectrophotometer in triplicate. The inhibition of the DPPH scavenging activity was calculated using the following formula:

$\%$ DPPH scavenging activity $=\left(1-\mathrm{A}_{517 \text { sample }} / \mathrm{A}_{517 \text { controo }}\right)$ $\times 100$ 
Where $A_{\text {control }}$ is the absorbance of all the reagents except the test sample, $A_{\text {sample }}$ is the absorbance of the EOs. Ascorbic acid was used as standard antioxidant. In order to determine $\mathrm{IC}_{50}$ values (scavenge $50 \%$ of the DPPH radicals) of the EOs, a linear regression analysis was used.

Lipid peroxidation activity assay by TBARS method: Lipid peroxidation activity was evaluated using thiobarbituric acid-reactive substances (TBARS) method described by Raharjo et al..$^{16}$ and Ferreira et al. ${ }^{17}$, 2-thiobarbituric acid (TBA) was used as indicator and 1,1,3,3-tetraethoxypropane (TEP) as standard. The absorbance of organic upper layer was read at $532 \mathrm{~nm}$ using a spectrophotometer in triplicate, and the TBARS values were expressed in terms of malondialdehyde (MDA) equivalents for quantifying lipid peroxides. The lipid peroxidation inhibition was calculated as;

Inhibition ratio $(\%)=\left(1-\mathrm{A}_{532 \text { sample }} / \mathrm{A}_{532 \text { control }}\right) \times 100$

Where $A_{\text {control }}$ is the absorbance of the control and $\mathrm{A}_{\text {sample }}$ is the absorbance of the sample solution. $\mathrm{IC}_{50}$ values (50\% of the lipid peroxidation inhibition) of the EOs were calculated and compared with the standard.

Statistical analysis: All the assays were conducted in triplicate, three different microplate wells were used to evaluate for each concentration of the EOs. A linear regression analysis was performed to calculate $\mathrm{IC}_{50}$ values. P value of $<0.01$ was considered statistically very significant.

\section{RESULTS AND DISCUSSION}

The EOs from $P$. alba L. and R. officinalis $\mathrm{L}$. were evaluated for their in vitro cytotoxic, antiproliferative, antioxidant and lipid peroxidation activities. Cytotoxicity $\left(\mathrm{IC}_{50}\right.$ values after $48 \mathrm{~h}$ treatment period) of the EOs from $P$. alba L. and R. officinalis L. to three cancer cell lines (A549, H1299, and MCF-7) and to the non-tumor HUVEC cells are given in the Table 1.

The EOs of P. alba L. and R. officinalis L. exhibited strong cytotoxic and antiproliferative properties against all the three tested human cancer cell lines, in a dose and time dependent manner. However, EO of R. officinalis was found to be more active $\left(\mathrm{IC}_{50}\right.$ values ranging from 3.06 to $7.38 \mu \mathrm{g} / \mathrm{mL}$ ) than that of P. alba $\left(\mathrm{IC}_{50}\right.$ values ranging from 12.05 to $28.16 \mu \mathrm{g} / \mathrm{mL}$ ). Interestingly, the EOs from both plants showed a selectivity toward the cancer cell lines, exhibiting strong activity against A459 and H1299 cells, moderate activity against MCF-7 and weak activity against the non-tumor HUVEC cells $\left(\mathrm{IC}_{50}>30 \mu \mathrm{g} / \mathrm{mL}\right)$. The strong growth inhibition of EO from R. officinalis could be due to the presence of the cytotoxic components such as carnasol, methyl carnosate, carnosic and rosmarinic acids. ${ }^{5,6-9}$ Although this is the first report of the cytotoxic and antiproliferative effects of the EO from P. alba, it is probable that saponins, which are present in this EO, could contribute to these effect. ${ }^{13}$

The results of in vitro antioxidant activity, expressed as $\mathrm{IC}_{50}$ values obtained from DPPH radical scavenging activity and lipid peroxidation activity by TBARS method, of the EOs from $P$. alba L. and R. officinalis L. are shown in Table 2. The EOs from both sources showed significant free radical scavenging activities against DPPH by when compared their values of $\mathrm{IC}_{50}$ with commercial with that of ascorbic acid, a commercial standard $\mathrm{AA}\left(\mathrm{IC}_{50}=12.64 \pm 0.32 \mu \mathrm{g} / \mathrm{mL}\right)$. The EO from $\mathrm{R}$. officinalis $\mathrm{L}$. was found to have higher free radical scavenging activity, with $\mathrm{IC}_{50}$ at $10.08 \pm 0.15 \mu \mathrm{g} / \mathrm{mL}$ $(\mathrm{p}<0.01), 18.05 \pm 0.38 \mu \mathrm{g} / \mathrm{mL}(\mathrm{p}<0.05)$ Polyphenols and phenylpropanoids, found in the rosemary oil are most likely responsible for a strong radical scavenging activity. ${ }^{7,9,20}$

The results of lipid peroxides radical scavenging capacity for both of the EOs, presented in Table 2, are consistent with the DPPH radical scavenging activity results. They were able to reduce the lipid peroxides radicals with $\mathrm{IC}_{50}$ of $1.76 \pm 0.02$ and $2.16 \pm 0.14$ respectively $(p<0.05)$. The values of $\mathrm{IC}_{50}$ were compared with the commercial standard BHT. This indicates that the rosemary and white poplar EOs were able to inhibit the free lipid

\begin{tabular}{|c|c|c|c|c|}
\hline \multirow{2}{*}{ Samples } & \multicolumn{4}{|c|}{$\mathrm{IC}_{50}$ values from MTT $(\mu \mathrm{g} / \mathrm{mL})$} \\
\hline & A549 & H1299 & MCF-7 & HUVEC \\
\hline R. officinalis $\mathrm{L}$. & $3.06 \pm 0.37$ & $4.34 \pm 0.44$ & $7.38 \pm 0.52$ & $30.68 \pm 2.80$ \\
\hline P. alba L. & $12.05 \pm 0.66$ & $10.53 \pm 0.38$ & $28.16 \pm 1.65$ & $42.02 \pm 2.04$ \\
\hline Doxorubicin ${ }^{a}$ & $0.25 \pm 0.01$ & $0.36 \pm 0.02$ & $0.82 \pm 0.05$ & $1.02 \pm 0.02$ \\
\hline $\mathrm{DMSO}^{\mathrm{b}}$ & 0 & 0 & 0 & 0 \\
\hline
\end{tabular}

Data are shown as means \pm SD from three independent experiments $(n=3)$.

aDoxorubicin, positive control.

'DMSO: negative control 
Table 2: The $I_{50}$ value of EOs of R. officinalis and $P$. alba, determined by

DPPH and TBARS assays

\begin{tabular}{|c|c|c|}
\hline Sample & IC $_{50}$ values from DPPH $(\boldsymbol{\mu g} / \mathbf{m L})$ & IC $_{50}$ values from TBARS $(\boldsymbol{\mu g} / \mathbf{m L})$ \\
\hline R. officinalis L. & $10.08 \pm 0.15^{*}$ & $1.76 \pm 0.02^{*}$ \\
\hline P. alba L. & $18.05 \pm 0.38^{*}$ & $2.16 \pm 0.14^{*}$ \\
\hline AA $^{\text {a }}$ & $12.64 \pm 0.32$ & Not determined \\
\hline BHT $^{\text {b }}$ & Not determined & $0.78 \pm 0.01$ \\
\hline
\end{tabular}

Data are shown as means $I C_{50}(\mu \mathrm{g} / \mathrm{mL})$ value from three independent experiments $(n=3)$.

${ }^{* *} \mathrm{P}$ value of $<0.01$, ${ }^{*} \mathrm{P}$ value of $<0.05$.

aA: Ascorbic acid, standard commercial antioxidant as positive control for DPPH assay.

bBHT: Butylated hydroxyl toluene, standard commercial antioxidant as positive control for TBARS assay.

peroxides radicals, as well as the activities of free radicals, this might be due to the fact that rich chemical compositions of the oils. ${ }^{5,13,20}$

\section{CONCLUSION}

However, further studies using cell culture and animal models to understand the mechanisms underlying the cytotoxicity and anticancer activity of these EOs are needed to better understand the biological events and molecular targets of EOs to safeguard their usage as therapeutic agents. In the near future, it would be possible to develop therapeutic drugs containing rosemary and white poplar EOs.

\section{ACKNOWLEDGMENTS}

The authors would like to thank Kilis 7 Aralik University, Central Laboratory for their technical support.

\section{CONFLICT OF INTERESTS}

The authors have declared that no conflict of interest exists.

\section{ABBREVIATIONS}

ATCC: American Type Culture Collection; BHT: Butylated hydroxyl toluene; DMSO: dimethyl sulphoxide; DPPH: 2,2-diphenyl-2-picrylhydrazyl; EOs: essential oils; IC $_{50}$ :inhibitoryconcentration $50 \%$;MAPs:medicinal and aromatic plants; MDA: malondialdehyde; MTT: [3-(4,5-dimethylthiazol-2-yl)-2,5-diphenyltetrazolium bromide]; OD: optical density; RPMI-1640 medium: roswell park memorial institute medium; TBARS: thiobarbituric acid-reactive substances; TEP: 1,1,3,3-tetraethoxypropane.

\section{REFERENCES}

1. Gupta R. Medicinal and Aromatic plants. CBS Publishers and Distributors. 2010;234:499.
2. Gautam N, Mantha AK, Mittal S. Essential oils and their constituents as anticancer agents: a mechanistic view. BioMed research international. 2014;2014:1-23.

3. Škrovánková S, Mišurcová L, Machu L. 3 Antioxidant Activity and Protecting Health Effects of Common Medicinal Plants. Advances in food and nutrition research. 2012;67:75.

4. Bayala B, Bassole IH, Scifo R, Gnoula C, Morel L, Lobaccaro J-MA, et al. Anticancer activity of essential oils and their chemical components-a review. American journal of cancer research. 2014;4(6):591.

5. Carvalho AA, Andrade LN, de Sousa ÉBV, de Sousa DP. Antitumor phenylpropanoids found in essential oils. BioMed research international. 2015;2015:1-21.

6. Begum A, Sandhya S, Vinod KR, Reddy S, Banji D. An in-depth review on the medicinal flora Rosmarinus officinalis (Lamiaceae). Acta Scientiarum Polonorum Technologia Alimentaria. 2013;12(1):61-74.

7. Moore J, Yousef M, Tsiani E. Anticancer Effects of Rosemary (Rosmarinus officinalis L.) Extract and Rosemary Extract Polyphenols. Nutrients. 2016;8(11):731.

8. Ngo SN, Williams DB, Head RJ. Rosemary and cancer prevention: preclinical perspectives. Critical reviews in food science and nutrition. 2011;51(10):946-54.

9. González-Vallinas M, Reglero G, Ramírez de Molina A. Rosemary (Rosmarinus officinalis L.) extract as a potential complementary agent in anticancer therapy. Nutrition and cancer. 2015;67(8):1223-31.

10. Cheung S, Tai J. Anti-proliferative and antioxidant properties of rosemary Rosmarinus officinalis. Oncology reports. 2007;17(6):1525-32.

11. Peng CH, Su JD, Chyau CC, Sung TY, Ho SS, Peng CC, et al. Supercritical fluid extracts of rosemary leaves exhibit potent anti-inflammation and antitumor effects. Bioscience, biotechnology, and biochemistry. 2007;71(9):2223-32.

12. Valdés A, García-Cañas V, Rocamora-Reverte L, Gómez-Martínez Á, Ferragut JA, Cifuentes A. Effect of rosemary polyphenols on human colon cancer cells: transcriptomic profiling and functional enrichment analysis. Genes \& nutrition. 2013;8(1):43-60.

13. Balestrazzi A, Carbonera D, Avato P, Tava A. White Poplar (Populus alba L.) Suspension Cultures as a Model System to Study Apoptosis Induced by Alfalfa Saponins. Anti-Cancer Agents in Medicinal Chemistry (Formerly Current Medicinal Chemistry-Anti-Cancer Agents). 2014;14(10):1324-31.

14. Al-Qubaisi M, Rozita R, Yeap SK, Omar AR, Ali AM, Alitheen NB. Selective cytotoxicity of goniothalamin against hepatoblastoma HepG2 cells. Molecules. 2011;16(4):2944-59.

15. Molyneux $P$. The use of the stable free radical diphenylpicrylhydrazyl (DPPH) for estimating antioxidant activity. Songklanakarin J Sci Technol. 2004;26(2):211-9.

16. Raharjo S, Sofos JN, Schmidt GR. Improved speed, specificity, and limit of determination of an aqueous acid extraction thiobarbituric acid-C18 method for measuring lipid peroxidation in beef. Journal of Agricultural and Food Chemistry. 1992;40(11):2182-5.

17. Ferreira IC, Aires E, Barreira JC, Estevinho LM. Antioxidant activity of Portuguese honey samples: Different contributions of the entire honey and phenolic extract. Food Chemistry. 2009;114(4):1438-43.

18. Cuvelier ME, Richard H, Berset C. Antioxidative activity and phenolic composition of pilot-plant and commercial extracts of sage and rosemary. Journal of the American Oil Chemists' Society. 1996;73(5):645-52. 
19. Kontogianni VG, Tomic G, Nikolic I, Nerantzaki AA, Sayyad N, Stosic-Grujicic $\mathrm{S}$, et al. Phytochemical profile of Rosmarinus officinalis and Salvia officinalis extracts and correlation to their antioxidant and anti-proliferative activity. Food Chemistry. 2013;136(1):120-9.
20. Ulbricht C, Abrams TR, Brigham A, Ceurvels J, Clubb J, Curtiss W, et al. An evidence-based systematic review of rosemary (Rosmarinus officinalis) by the Natural Standard Research Collaboration. Journal of dietary supplements. 2010;7(4):351-413.

\section{PICTORIAL ABSTRACT}
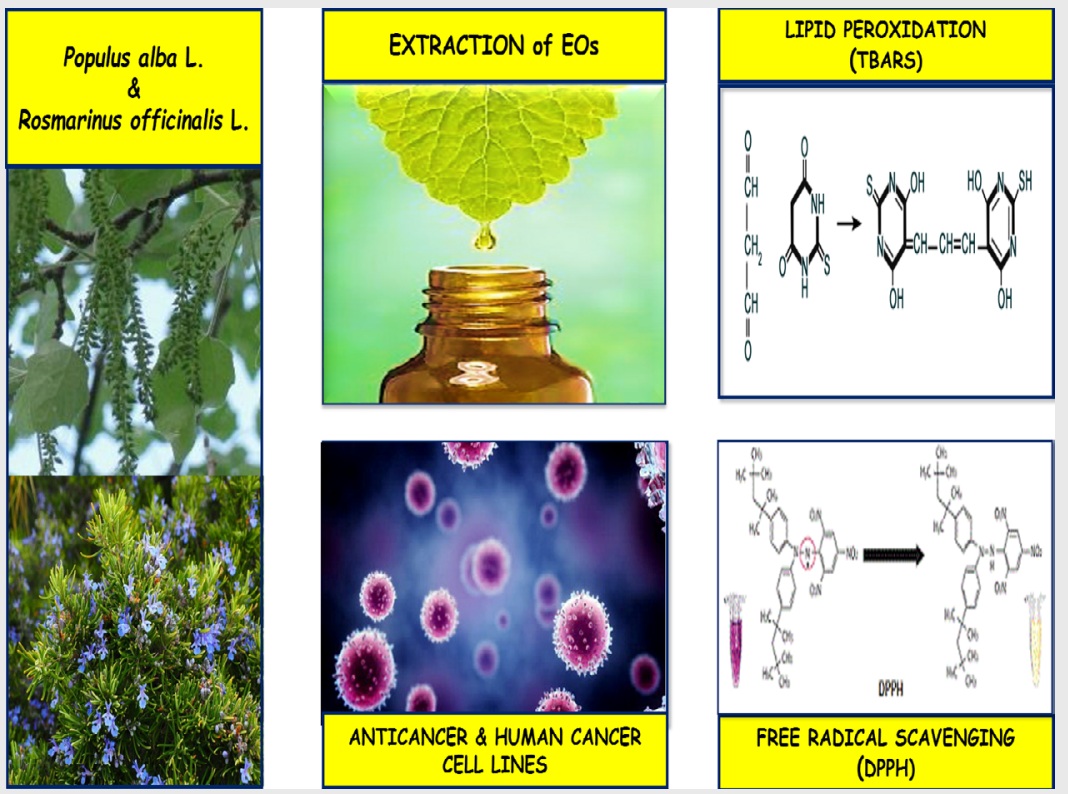

\section{SUMMARY}

- EOs extracted from MAPs, are valuable sources due to their interesting anti-tumor, antimutagenic and anti-carcinogenic activities against various cancer cells.

- Potential antioxidant properties, lipid peroxidation capacity, in vitro cytotoxic and antiproliferative activities of EOs extracted from $P$. alba L. and $R$. officinalis L. were evaluated in this research.

- To the best of our knowledge, this is the first report of EO of $P$. alba in vitro anticancer and antiproliferative activities.

- As a result, both of the EOs exhibited strong cytotoxic and antiproliferative properties against tested cancer cell lines.

- Regarding antioxidant and lipid peroxidation activity, EO from $R$. officinalis L. was found to have higher antioxidant and lipid peroxidation capacities.

- This research clearly showed these oils have significant potential for developing therapeutic drugs in pharmaceutical industry.

\section{ABOUT AUTHORS}

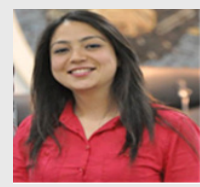

Dr. Sevgi Gezici: After completing her Ms in Molecular Biology and Genetic at Department of Biology, Gaziantep University, Turkey, she earned her Ph.D degree in the Molecular Biology and Genetics form the same University. She has received scholarships for her MSc and Ph.D from TUBITAK, which is the best research center in Turkey. She is currently doctor at Gaziantep University, Department of Molecular Biology. 


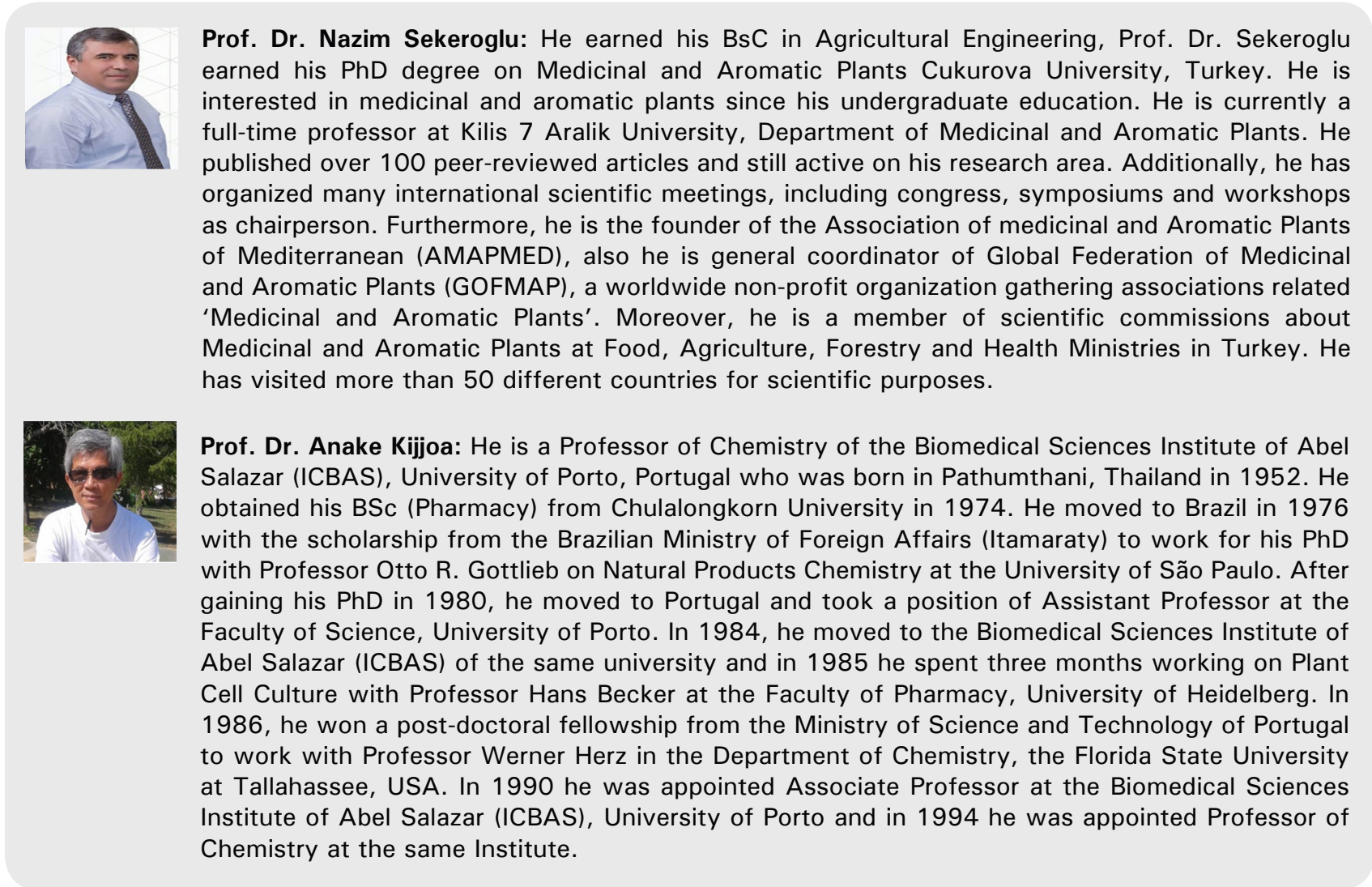

Cite this article: Gezici S, Sekeroglu N, Kijjoa A. In vitro Anticancer Activity and Antioxidant Properties of Essential Oils from Populus alba L. and Rosmarinus officinalis L. from South Eastern Anatolia of Turkey. Indian J of Pharmaceutical Education and Research. 2017;51(3)Suppl:S498-503. 